\title{
Plumbagin Enhances the Radiosensitivity of Tongue Squamous Cell Carcinoma Cells via Downregulating ATM
}

\author{
Shu-Ting Pan (D, Gan Huang, Qiaohong Wang, and Jia-Xuan Qiu $(\mathbb{1})$ \\ Department of Oral and Maxillofacial Surgery, The First Affiliated Hospital of Nanchang University, Nanchang 330006, \\ Jiangxi, China \\ Correspondence should be addressed to Jia-Xuan Qiu; qiujiaxuan@163.com
}

Received 14 May 2021; Accepted 18 August 2021; Published 27 August 2021

Academic Editor: Yongzhong Hou

Copyright ( 2021 Shu-Ting Pan et al. This is an open access article distributed under the Creative Commons Attribution License, which permits unrestricted use, distribution, and reproduction in any medium, provided the original work is properly cited.

This study was designed to investigate whether plumbagin (PL) could sensitize ionizing radiation (IR) in tongue squamous cell carcinoma (TSCC) cells and its possible mechanisms. Cell proliferation and combination index analysis was based on MTT and colony formation assay. Flow cytometry was applied to analyze the cell cycle distribution and apoptosis after the treatment of PL and/or IR. RT-PCR was used to examine the gene expression level of ataxia telangiegatasiata muted (ATM) and nuclear factor kappa beta (NF- $\kappa \mathrm{B})$ after various treatment groups. Western blot was used to examine the protein level of ATM and NF- $\kappa B$ as well as their phosphorylation level. PL enhances the cytotoxicity of IR in TSCC cells. Combination index was $<1$ which represents a synergistic effect. Combined PL and IR promoted G2/ $\mathrm{M}$ arrest and apoptosis which could be reversed by ATM activator chloroquine phosphate. ATM and NF- $\kappa \mathrm{B}$ were both inhibited by PL and IR combination. PL can efficiently enhance the radiosensitivity of TSCC cells by inducing G2/M arrest and apoptosis via downregulating ATM.

\section{Introduction}

The prevalent pathological type of tongue cancers is squamous cell carcinoma (TSCC) of which the incidence has been increasing since the 2000s [1]. TSCC has the characteristics of rapid development, early metastasis, and high lethal rate. Although there has been advancement in the comprehensive therapies, the patients still suffer from serious relapse and $50 \%$ of patients die within 5 years after diagnosis [2].

The existence of radiation resistance greatly hampers the treatment efficacy of cancer [3]. One of the main reasons is the enhanced DNA repair ability in cancer cells which may affect the cell cycle and apoptotic cell death. The ATM gene is the main transducer of the DNA damage response. ATM can identify DNA damage sites, initiate DNA damage response, and recruit downstream proteins to repair damaged DNA [4]. Except for ATM, nuclear factor kappa beta (NF$\kappa \mathrm{B})$ is another important transducer of DNA damage [5].
Abnormal activation of NF- $\mathrm{KB}$ will lead to the radioresistance and relapse of human cancers [6].

In the past decades, natural products from herbs have emerged as potent anticancer strategies used either alone or in combination with chemotherapy or radiotherapy in order to overcome resistance [7]. Plumbagin (PL) is an important bioactive secondary metabolite isolated from the root of Plumbago zeylanica L. which possesses anticancer activities [8]. Previous studies from us and other groups have shown that PL regulates cell cycle, apoptosis, and autophagy in various cancer cells, such as hepatocellular carcinoma [9], breast cancer [10], and tongue cancer [11]. PL can also enhance the anticancer efficacy of chemotherapeutic drugs such as cisplatin and paclitaxel through modulation of p53 and MAPKs pathways [12-14]. However, the sensitizing effect of PL on radiation of TSCC is not clear. In the present study, we aimed to determine the radiosensitizing effect of PL on TSCC cells as well as the mechanisms. 


\section{Materials and Methods}

2.1. Chemicals and Reagents. PL was bought from SigmaAldrich Co. (USA). DMEM/F-12 medium, DMSO, fetal bovine serum (FBS), MTT, crystal violet, PBS, BSA, RIPA buffer, protease inhibitor cocktail, and PVDF were purchased from Solarbio Co. (China). Primary antibodies against ATM (\#92356S, mouse mAb), p-ATM (\#13050S, rabbit $\mathrm{mAb}), \mathrm{NF}-\kappa \mathrm{B}(\# 8242 \mathrm{~S}$, rabbit $\mathrm{mAb})$, and $\mathrm{p}-\mathrm{NF}-\kappa \mathrm{B}$ (\#3039S, rabbit $\mathrm{mAb}$ ) were bought from Cell Signaling Technology Inc. (USA). All these antibodies were diluted into $1: 1000$. Primary antibody against $\beta$-actin (\#660009-1$\mathrm{lg}$, mouse $\mathrm{mAb}$ ) was purchased from Proeintech Inc. (USA). The dilution rate was $1: 5000$. Horseradish peroxidaseconjugated affinipure goat anti-rabbit lgG (\#SA00001-2) and goat anti-mouse $\lg$ (\#SA00001-1) were purchased from Proteintech Inc. (USA). All the secondary antibodies were diluted to $1: 2000$. KU-55933 (KU) and chloroquine phosphate (CQ) were bought from Selleck Co. (USA).

2.2. Cell Line and Culture Conditions. TSCC cell line SCC9 was donated by the laboratory of Wuhan University, and CAL27 was bought from the Cell Bank of the Chinese Academy of Sciences (China). Cells were cultured with the DMEM/F-12 medium containing 10\% (v/v) FBS, $100 \mu \mathrm{g} / \mathrm{ml}$ streptomycin, and $100 \mathrm{U} / \mathrm{ml}$ penicillin at $37^{\circ} \mathrm{C}$ in a $5 \% \mathrm{CO}_{2} /$ 95\% humidified incubator.

2.3. Irradiation. TSCC cells were irradiated in a Primus X-ray linear accelerator $6 \mathrm{MV}$ (Siemens, Germany) with a $2 \mathrm{~Gy} / \mathrm{min}$ absorption dose rate and a $3 \mathrm{~cm}$ irradiation depth. The radiation dose was set separately according to the needs of each experiment. The irradiation field covers the whole cell culture plate, and two solid-water blocks $(2 \mathrm{~cm}$ thickness) were placed on the top and bottom of the Petri dish. Cells were then incubated after radiation for next experiments.

2.4. Cell Viability Assay. MTT was applied to examine the effect of PL and/or IR on cell viability. TSCC cells were seeded into 96-well plates at a density of $5 \times 10^{3}$ for incubation. After $24 \mathrm{hr}$, the cells were treated with PL at $0.625-20 \mu \mathrm{M}$ and/or IR at $1-8 \mathrm{~Gy}$ for 12,24 , and $48 \mathrm{hr}$. Then, a volume of $10 \mu \mathrm{L}$ of MTT solution was added to each well, and the plates were incubated for a further $3 \mathrm{hr}$. The solution was then removed, and $100 \mu \mathrm{L}$ DMSO was added to dissolve the crystal. The optical density (OD) was measured at the wavelengths of $560 \mathrm{~nm}$ and $670 \mathrm{~nm}$ using a Synergy ${ }^{\mathrm{TM}} \mathrm{H} 4$ Hybrid microplate reader (BioTek, Inc., USA). Cell viability was calculated as a percentage of the control. Cell viability $(\%)=(\mathrm{OD}$ treatment-OD blank $) /(\mathrm{OD}$ control-OD blank) $\times 100 \%$. The median inhibitory concentration $\left(\mathrm{IC}_{50}\right)$ was calculated from the growth inhibition curves fitted to the data using GraphPad Prism 5 software.

2.5. Combination Index Analysis. The combination effect of PL and IR on TSCC cells was evaluated using the combination index (CI) according to the median dose-effect analysis by Chou and Talalay [15]. We designed 16 doseeffect points in a nonconstant ratio manner (Table 1). Fractional inhibition (FA) $=1$-fraction of surviving cells. The corresponding CI values were analyzed using the CompuSyn Software (ComboSyn, Inc., USA). CI $<1$ represents a synergistic effect; $\mathrm{CI}=1$ represents an additive cytotoxicity; and $\mathrm{CI}>1$ represents an antagonistic effect.

2.6. Colony Formation Assay. TSCC cells were seeded in sixwell plates at a density of 500 cells/well. After $24 \mathrm{hr}$ incubation, cells were treated with IR or PL alone or PL (pretreated for $1 \mathrm{hr})+\mathrm{IR}$. After 2 weeks, the medium was removed and cells were washed with PBS, fixed with $4 \%$ paraformaldehyde, and stained with $0.1 \%$ crystal violet for 30 min. Colonies with more than 50 cells were scored and counted under the microscope.

2.7. Cell Cycle Distribution Analysis. TSCC cells were seeded in six-well plates at a density of $1 \times 10^{5}$ cells $/ \mathrm{ml}$ for attaching overnight. Then, cells were treated with IR or PL alone or PL (pretreated for $1 \mathrm{hr}$ ) $+\mathrm{IR}$. After $24 \mathrm{hr}$, cells were trypsinized and fixed with cold $70 \%$ ethanol overnight. The Cell Cycle detection kit (KeyGEN BioTECH Co., China) containing PI and RNase was used to incubate the cells for $30 \mathrm{~min}$. A total of $1 \times 10^{4}$ events were subjected to cell cycle analysis by flow cytometry (BD ${ }^{\mathrm{TM}}$ LSR II Analyzer, USA).

2.8. Apoptosis Assay. TSCC cells were seeded in six-well plates at a density of $1 \times 10^{5}$ cells $/ \mathrm{ml}$ for attaching overnight. Then, cells were treated with IR or PL alone or PL (pretreated for $1 \mathrm{hr}$ ) + IR. After $24 \mathrm{hr}$, cells were trypsinized and washed twice with cold PBS. The Annexin V: PE/7-AAD apoptosis detection kit (BD Biosciences Inc., USA) containing annexin $\mathrm{V}$ : PE and 7-AAD was used to bind the cells for $15 \mathrm{~min}$ at room temperature. $1 \times$ binding buffer $(400 \mu \mathrm{L})$ was added to each test tube, and the apoptosis number was quantified by flow cytometry (BD ${ }^{\mathrm{TM}}$ LSR II Analyzer, USA).

2.9. Real-Time Polymerase Chain Reaction. Total RNA was extracted from TSCC cells based on the protocol of TRIzol reagent. The collected RNA was used to synthesize cDNA with a reverse transcription kit (Takara, Japan). The reaction condition was $37^{\circ} \mathrm{C}$ for $15 \mathrm{~min}$ and $85^{\circ} \mathrm{C}$ for $15 \mathrm{~s}$. For measuring the mRNA levels of ATM and NF- $\kappa B$, real-time quantitative PCR was performed with the SYBR Premix Ex Taq kit (QIAGEN, Germany) in a DNA Engine Opticon 2 system (Bio-Rad, USA). The mRNA level of $\beta$-actin was used to standardize the mRNA levels. The reaction procedures were denaturation at $95^{\circ} \mathrm{C}$ for $5 \mathrm{~min}, 40$ cycles at $95^{\circ} \mathrm{C}$ for $30 \mathrm{~s}$, and $60^{\circ} \mathrm{C}$ for $45 \mathrm{~s}$. The comparative CT method $(\Delta \Delta \mathrm{CT})$ was used to compute the relative variations in gene expression. The sequences of primers for ATM, NF- $\mathrm{B}$, and $\beta$-actin are provided as follows: $\beta$-actin: Forward-5'-CGTGGACATCC TAAAGACC- $3^{\prime}$, Reverse- $5^{\prime}$ ACATCTGCTGGAAGGTGGAC- $3^{\prime}$; ATM: Forward- $5^{\prime}$ CGTGCCAGAATGTGAACACC-3', Reverse-5'-A GCCAATACTGGACTGGTGC- $3^{\prime}$; and NF- $\kappa$ B: Forward $-5^{\prime}-$ 
TABLE 1: CI of various concentrations of PL combined with four doses of IR.

\begin{tabular}{|c|c|c|c|c|c|c|c|c|c|}
\hline \multirow{2}{*}{$\begin{array}{l}\text { SCC9 } \\
\text { PL }(\mu \mathrm{M})\end{array}$} & \multirow[b]{2}{*}{ IR (Gy) 0} & \multicolumn{4}{|c|}{ FA } & \multicolumn{4}{|c|}{$\mathrm{CI}$} \\
\hline & & 1 & 2 & 4 & 8 & 1 & 2 & 4 & 8 \\
\hline 0 & - & 0.067 & 0.108 & 0.289 & 0.398 & - & - & - & - \\
\hline 1.25 & 0.084 & 0.188 & 0.322 & 0.479 & 0.497 & 0.901 & 0.708 & 0.626 & 0.967 \\
\hline 2.5 & 0.217 & 0.287 & 0.349 & 0.511 & 0.561 & 0.987 & 0.967 & 0.771 & 0.961 \\
\hline 5 & 0.488 & 0.498 & 0.521 & 0.587 & 0.655 & 0.949 & 0.977 & 0.946 & 0.979 \\
\hline 10 & 0.661 & 0.711 & 0.732 & 0.791 & 0.812 & 0.976 & 0.948 & 0.816 & 0.847 \\
\hline \multicolumn{2}{|l|}{ CAL27 } & \multicolumn{4}{|c|}{ FA } & \multicolumn{4}{|c|}{ CI } \\
\hline $\mathrm{PL}(\mu \mathrm{M})$ & $\mathrm{IR}(\mathrm{Gy}) 0$ & 1 & 2 & 4 & 8 & 1 & 2 & 4 & 8 \\
\hline 0 & - & 0.065 & 0.109 & 0.352 & 0.412 & - & - & - & - \\
\hline 1.25 & 0.078 & 0.179 & 0.341 & 0.398 & 0.505 & 0.944 & 0.692 & 0.882 & 1.058 \\
\hline 2.5 & 0.210 & 0.291 & 0.345 & 0.512 & 0.612 & 0.967 & 0.997 & 0.816 & 0.902 \\
\hline 5 & 0.473 & 0.501 & 0.526 & 0.652 & 0.668 & 0.929 & 0.968 & 0.802 & 1.007 \\
\hline 10 & 0.651 & 0.712 & 0.745 & 0.801 & 0.813 & 0.956 & 0.899 & 0.792 & 0.882 \\
\hline
\end{tabular}

AACAGCAGA TGGCCCATACCT-3', Reverse-5' -ACGCTGAGGTCCATCTCCT TG-3'.

2.10. Western Blot Analysis. TSCC cells were seeded in sixwell plates at a density of $1 \times 10^{5}$ cells $/ \mathrm{ml}$ for attaching overnight. Then, cells were treated with IR or PL alone or PL (pretreated for $1 \mathrm{hr}$ ) + IR. After $24 \mathrm{hr}$, cells were washed with PBS and lysed with RIPA buffer. Nuclear proteins were extracted using the nuclear protein extraction kit (Beyotime Co., China). Protein concentrations were measured by using the BCA protein assay kit (Beyotime Co., China). Equal amounts of protein samples were electrophoresed on 8-10\% sodium dodecyl sulfate polyacrylamide gel electrophoresis (SDS-PAGE). Proteins were transferred onto an immobilon PVDF membrane at $100 \mathrm{~V}$ for $2 \mathrm{hr}$ at $4^{\circ} \mathrm{C}$. Membranes were probed with primary antibodies overnight at $4^{\circ} \mathrm{C}$ and then blotted with secondary antibodies for $2 \mathrm{hr}$. Super ECL Star (US Everbright, Inc.) and the UVP ChemStudio Imaging System (Analytik Jena, Germany) were employed to examine the electrochemiluminescence of indicated proteins.

2.11. Statistical Analysis. All the experimental data are presented as mean \pm standard deviation (SD) in triplicates. Multiple comparisons were evaluated by one-way analysis of variance (ANOVA) followed by Tukey's post hoc test. GraphPad Prism 5 software was used for statistical analysis. $p<0.05$ was considered statistically significant.

\section{Results}

3.1. PL Inhibits the Proliferation and Enhances the Radiosensitivity of TSCC Cell Lines. As shown in Figures 1(a) and 1(d), PL treatment decreased the viability of TSCC cells in a dose- and time-dependent manner. After 12, 24, and $48 \mathrm{hr}$ treatment, the $\mathrm{IC}_{50}$ of PL in SCC9 cells was 10.3, 5.8, and $4.8 \mu \mathrm{M}$; the $\mathrm{IC}_{50}$ of PL in CAL27 cells was $11.1,6.2$, and $5.1 \mu \mathrm{M}$, respectively.

We then explored whether PL could enhance IR sensitivity of TSCC cells. We tested the combined effect of PL $(1.25,2.5,5$, and $10 \mu \mathrm{M})$ with IR $(1,2,4$, and 8 Gy) on TSCC cells. As illustrated in Figures 1(b), 1(c), 1(e), and 1(f) and
Table 1, the combination treatment significantly increased the IR sensitivity in TSCC cells. In addition, CI values showed that the combination of PL and IR exerted synergistic cytotoxic effects at all tested points in SCC9 cells and at most tested points in CAL27 cells (Table 1). Noteworthy, the combination of $1.25 \mu \mathrm{M}$ PL and 4 Gy IR exhibited the lowest $\mathrm{CI}$ value $(\mathrm{CI}=0.626)$ in SCC9 cells and the combination of $1.25 \mu \mathrm{M}$ PL and 2 Gy IR exhibited the lowest CI value $(\mathrm{CI}=0.692)$ in CAL27 cells which indicated the best synergistic effect.

Based on the aforementioned data, we selected the dose of $1.25 \mu \mathrm{M}$ PL and 4 Gy IR for SCC9 cells and $1.25 \mu \mathrm{M}$ PL and $2 \mathrm{~Gy}$ IR for CAL27 cells in the next experiments. Colony formation assay showed that the combination of PL and IR could significantly decrease the number of colonies by $44.81 \%$ in SCC9 cells and 55.82\% in CAL27 cells, compared with IR single treatment (Figures $1(\mathrm{~g})-1(\mathrm{j}) ;{ }^{* * *} p<0.001$ ). These results showed that PL significantly radiosensitized the TSCC cells.

3.2. Combined PL and IR Promote G2/M Arrest in TSCC Cells. To probe the mechanisms of synergism between PL and IR in TSCC cells, we first detected the cell cycle distribution by PI staining and flow cytometry. SCC9 cells were treated with $1.25 \mu \mathrm{M}$ PL and/or 4 Gy IR for $24 \mathrm{hr}$, while CAL27 cells were treated with $1.25 \mu \mathrm{M}$ PL and/or $2 \mathrm{~Gy}$ IR for $24 \mathrm{hr}$. In SCC9 cells, compared with the IR single group, the PL and IR combination group significantly increased the G2/M phase by 1.89 -fold (Figures 2 (a), 2(c), and $2(\mathrm{~d}){ }^{* * *} p<0.001$ ). In CAL27 cells, compared with the IR single group, the PL and IR combination group significantly increased the G2/M phase by 1.76-fold (Figures 2(b), 2(e), and 2(f); $\left.{ }^{* * *} p<0.001\right)$. Collectively, these results show that combination PL and IR treatment modulates cell cycle rendering TSCC cells less proliferative in a potent and synergistic manner.

3.3. PL Enhances IR-Induced Apoptosis in TSCC Cells. We next examined whether PL could affect the cellular apoptosis and whether apoptosis is a mechanism of synergism between PL and IR. SCC9 cells were treated with $1.25 \mu \mathrm{M}$ PL and/or 


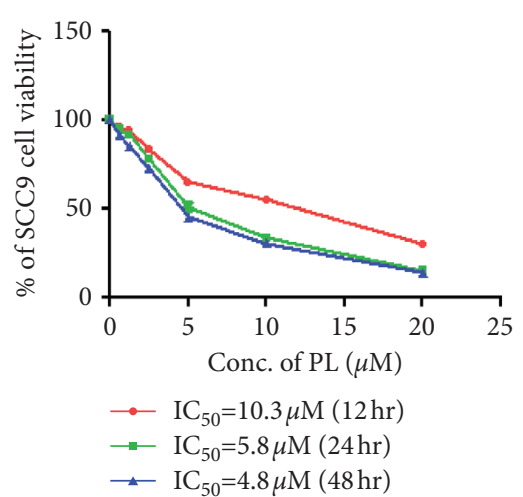

(a)

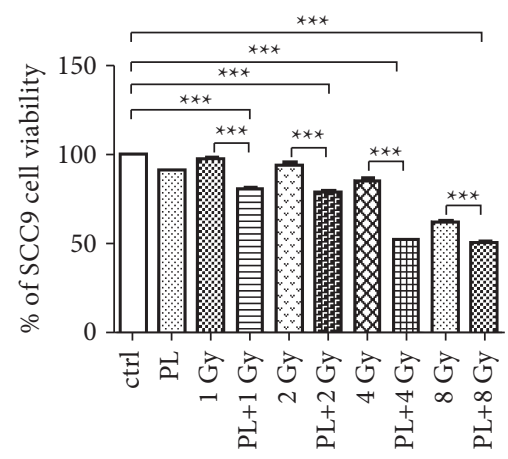

(c)

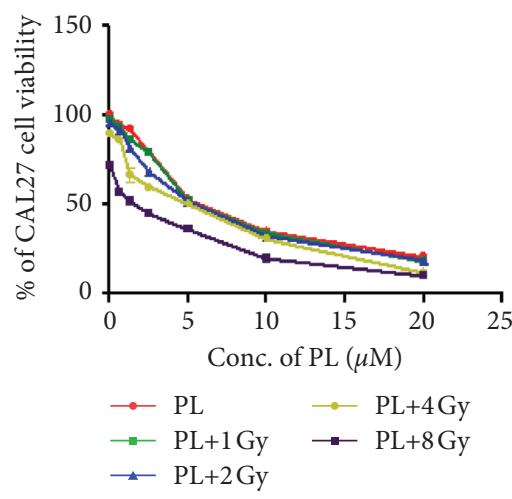

(e)

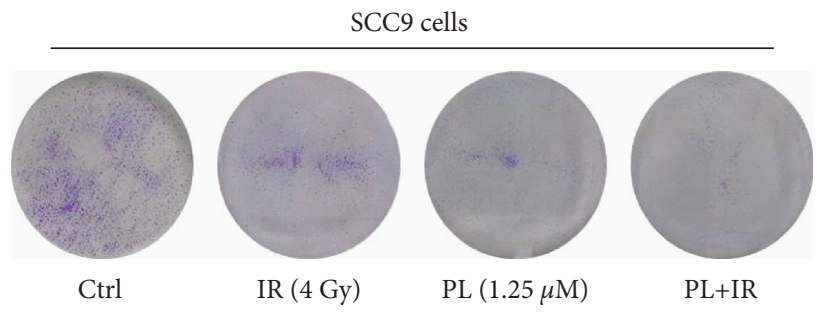

(g)

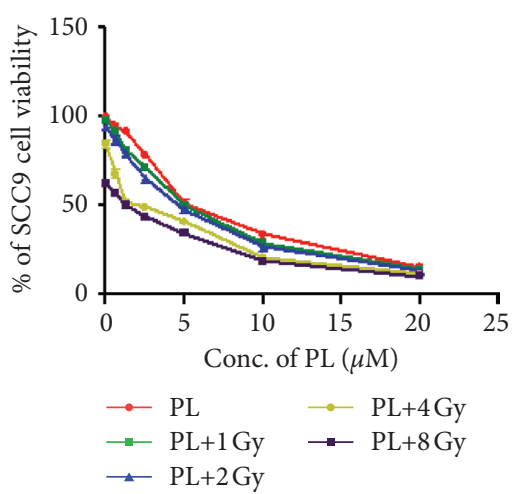

(b)

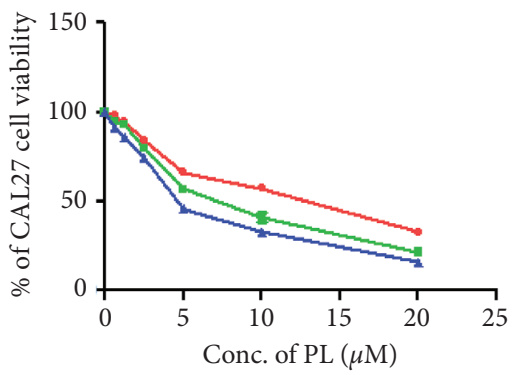

$\rightarrow \mathrm{IC}_{50}=11.1 \mu \mathrm{M}(12 \mathrm{hr})$

- $\mathrm{IC}_{50}=6.2 \mu \mathrm{M}(24 \mathrm{hr})$

$\multimap \mathrm{IC}_{50}=5.1 \mu \mathrm{M}(48 \mathrm{hr})$

(d)

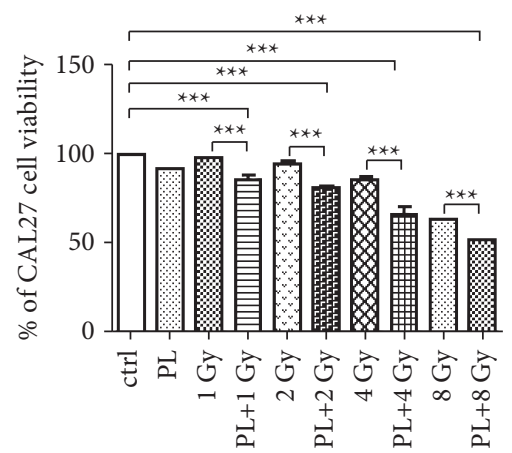

(f)

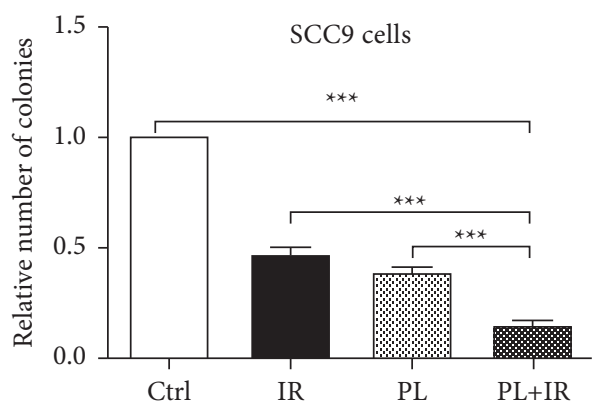

(h)

FIgure 1: Continued. 

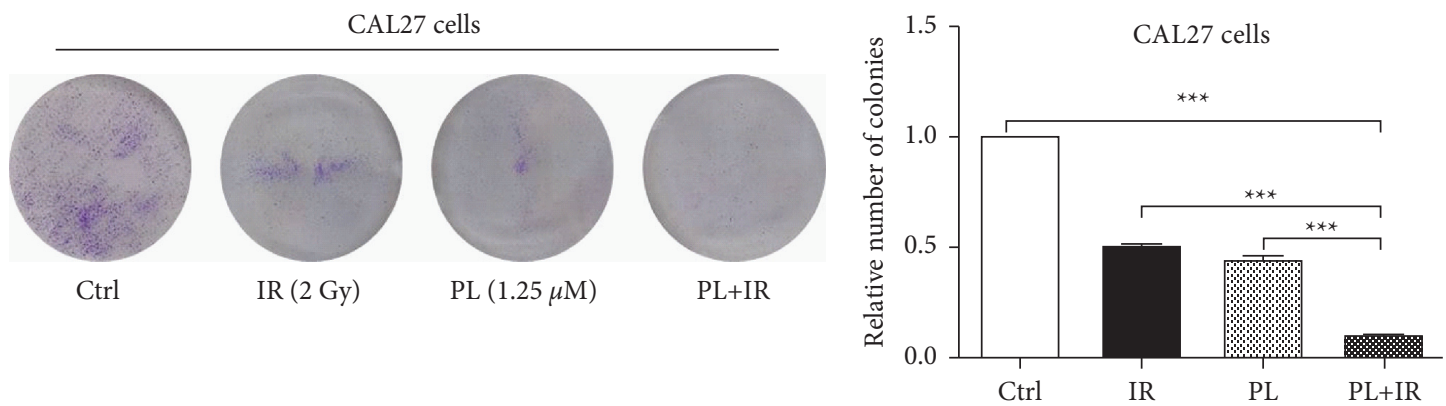

(i)

$(\mathrm{j})$

FIgURE 1: The effect of PL and/or IR on TSCC cell viability. (a, d) SCC9 and CAL27 cells were treated with 0.625-20 $\mu \mathrm{M}$ PL for 12, 24, and $48 \mathrm{hr}$. (b, e) Combination treatment of various doses of PL and IR for $24 \mathrm{hr}$ in SCC9 and CAL27 cells. (c, f) Histograms of the cell viability after the combination treatment of $1.25 \mu \mathrm{M}$ PL and 1-8 Gy IR for $24 \mathrm{hr}$. (g, i) SCC9 and CAL27 cells were treated with IR, PL, and IR + PL for $24 \mathrm{hr}$. (h, j) Colony formation quantification of TSCC cells with PL or combined with IR. ${ }^{* * *} p<0.001$.

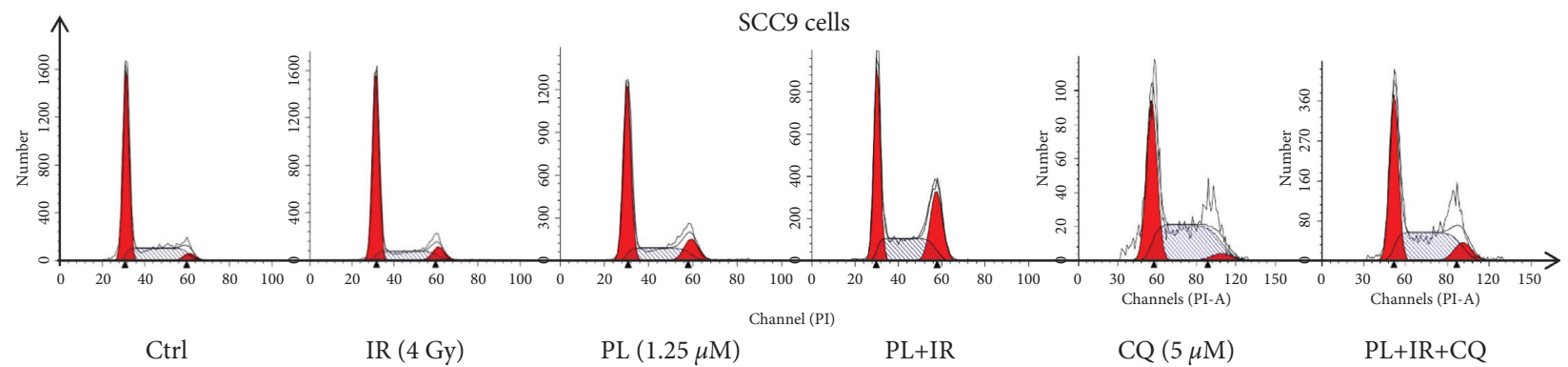

(a)

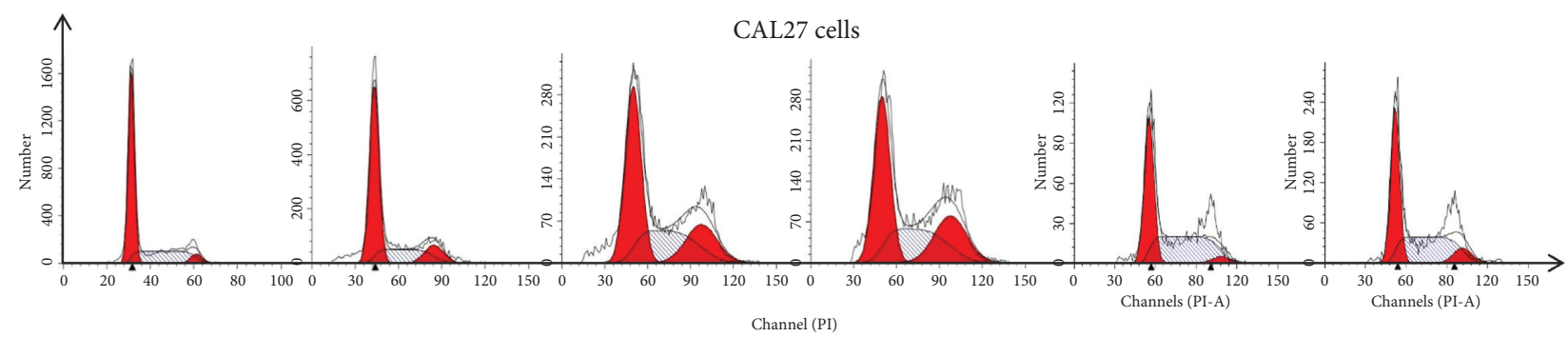

Ctrl

IR (2 Gy)

PL $(1.25 \mu \mathrm{M})$

PL+IR

CQ $(5 \mu \mathrm{M})$

$\mathrm{PL}+\mathrm{IR}+\mathrm{CQ}$

(b)

SCC9 cells

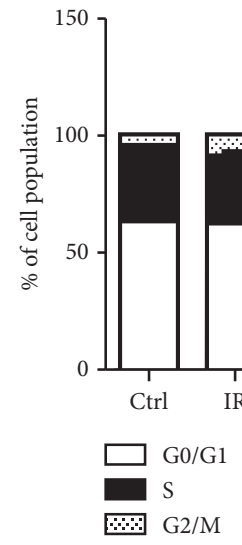

SCC9 cells

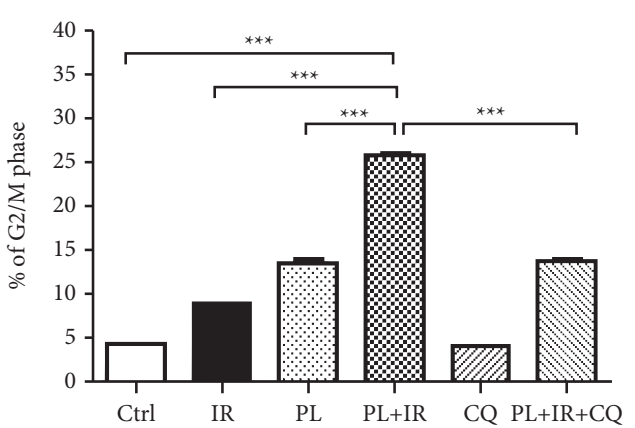

(c)

(d)

Figure 2: Continued. 


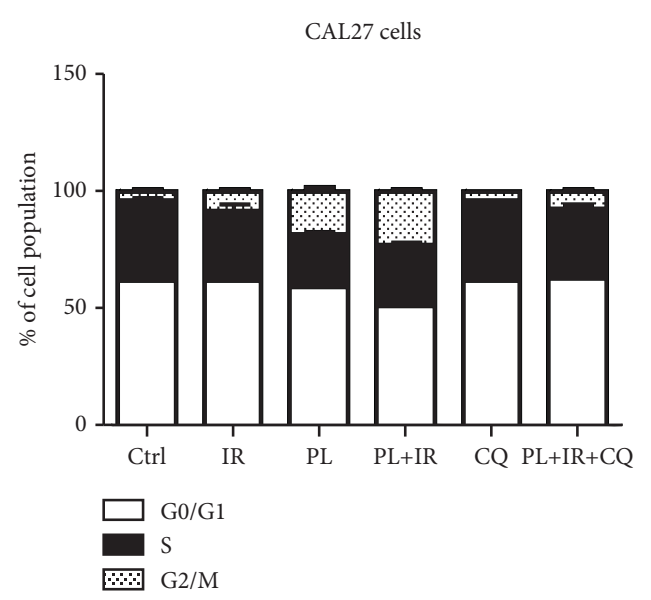

(e)

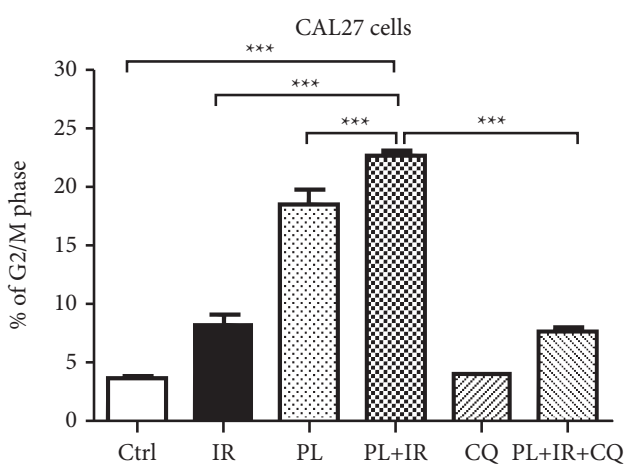

(f)

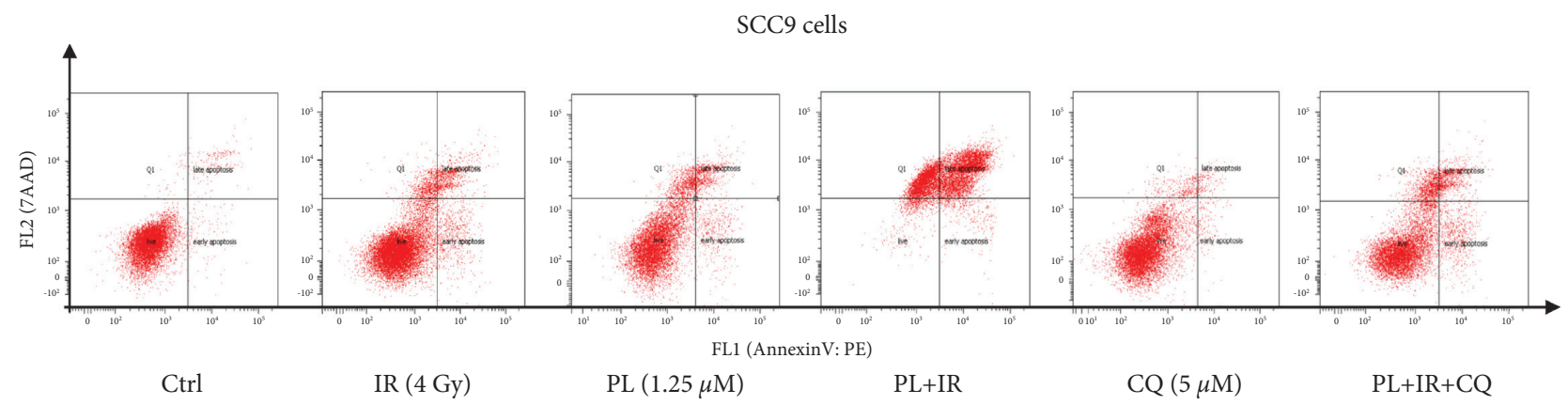

(g)

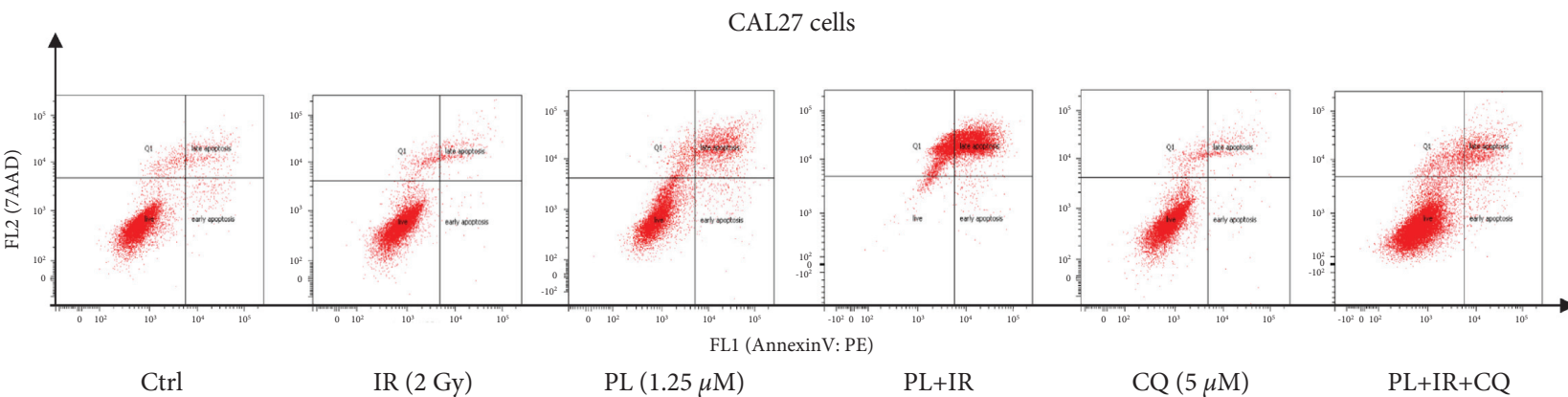

(h)

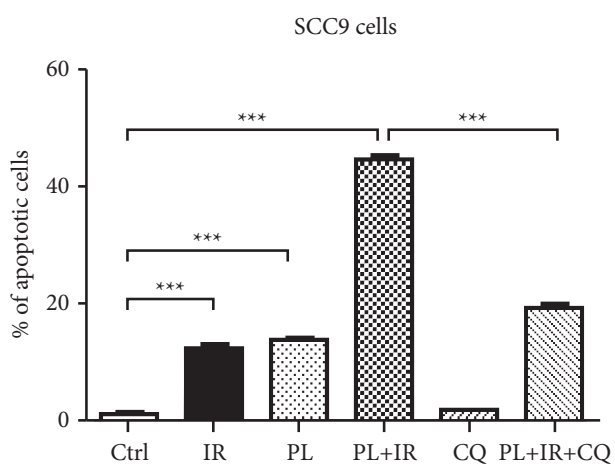

(i)

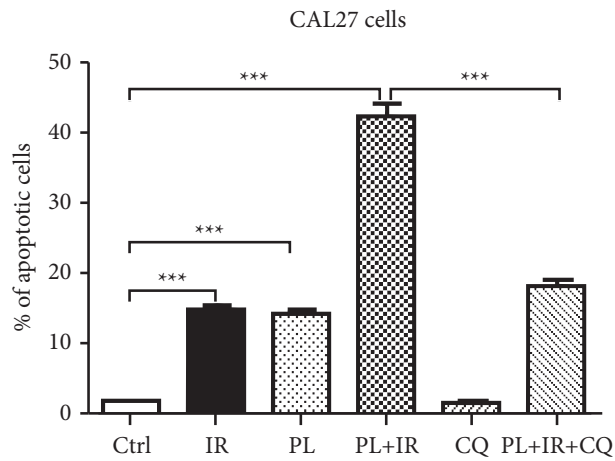

(j)

FIGURE 2: Combined PL and IR treatment promotes G2/M arrest and apoptosis in TSCC cells. (a) Representative flow cytometric plots of cell cycle distribution of SCC9 cells and (c-d) bar graph showing the percentage of TSCC cells in G0/G1, S, and G2/M phases after the treatment of $4 \mathrm{~Gy} \mathrm{IR}, 1.25 \mu \mathrm{M}$ PL, and the combination of $4 \mathrm{~Gy}$ IR with $1.25 \mu \mathrm{M}$ PL for $24 \mathrm{hr}$. (b) Representative flow cytometric plots of cell cycle distribution of CAL27 cells and (e-f) bar graph showing the percentage of CAL27 cells in G0/G1, S, and G2/M phases after the treatment of 2 Gy IR, $1.25 \mu \mathrm{M}$ PL, and the combination of 2 Gy IR with $1.25 \mu \mathrm{M}$ PL for $24 \mathrm{hr}$. (g-h) Representative flow cytometric plots of apoptosis of SCC9 and CAL27 cells and (i-j) bar graph showing the percentage of total apoptosis in SCC9 and CAL27 cells after the treatment of IR, PL, and IR + PL for $24 \mathrm{hr} .{ }^{* * *} p<0.001$. 


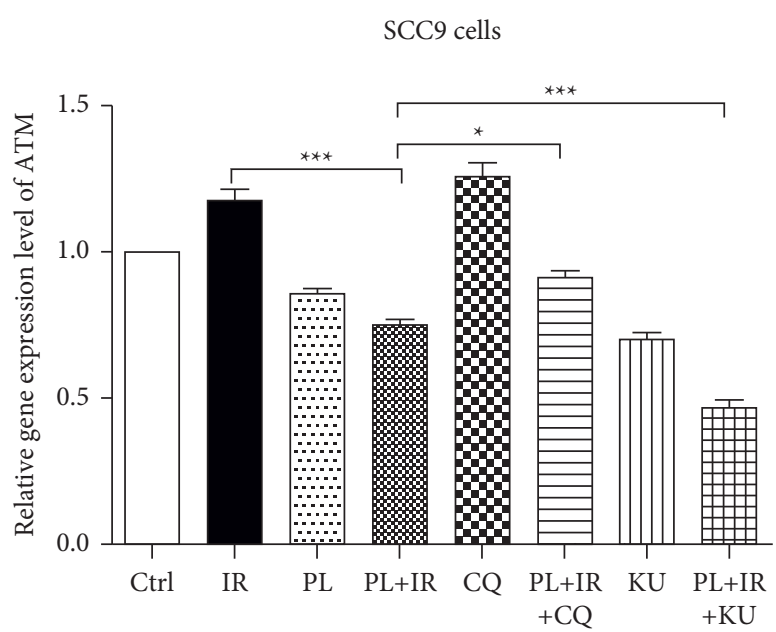

(a)

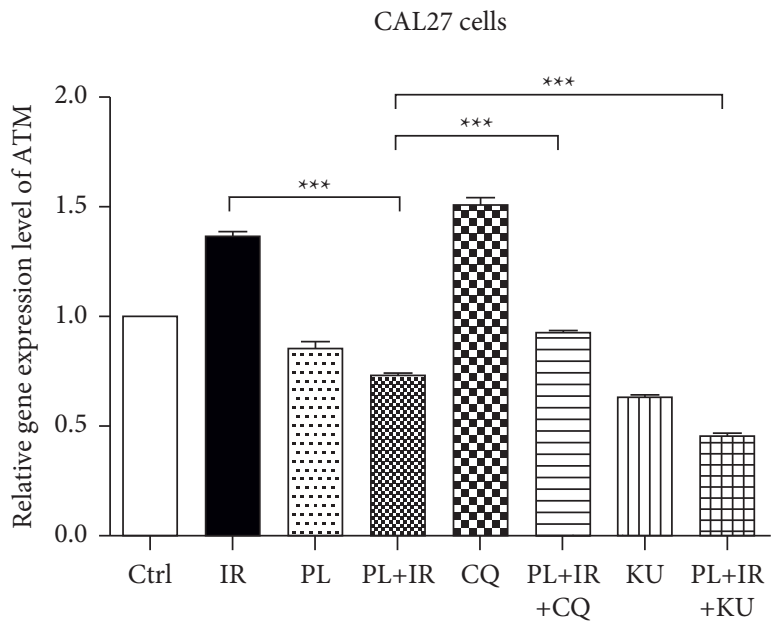

(c)

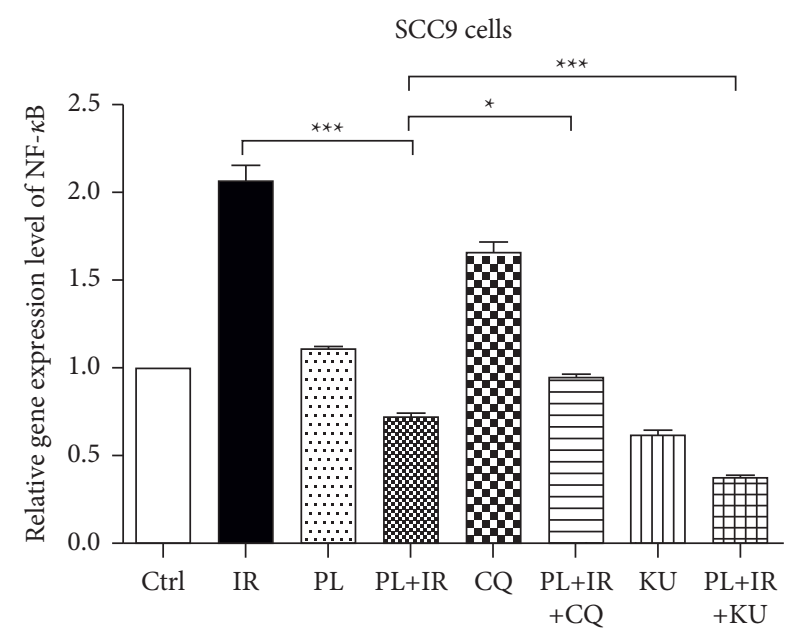

(b)

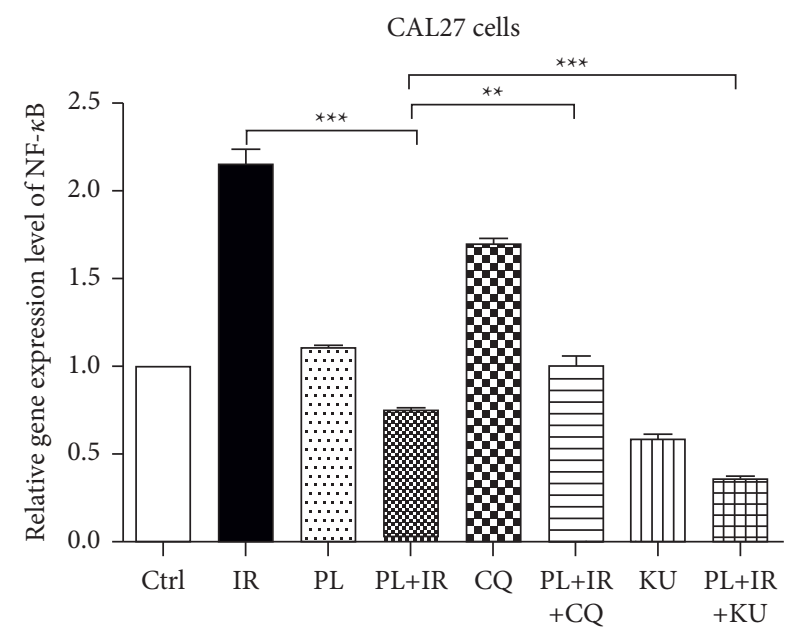

(d)

Figure 3: mRNA level of ATM and NF- $\kappa B$ after the pretreatment of ATM activator CQ or ATM inhibitor KU in TSCC cells. (a-b) Relative mRNA level of ATM and NF- $\mathrm{B}$ in SCC9 cell after the treatment of $1.25 \mu \mathrm{M}$ PL and 4 Gy IR with or without pretreatment of $5 \mu \mathrm{M}$ CQ or $100 \mathrm{nM}$ KU. (c-d) Relative mRNA level of ATM and NF- $\kappa B$ in CAL27 cell after the treatment of $1.25 \mu \mathrm{M}$ PL and 2 Gy IR with or without pretreatment of $5 \mu \mathrm{M}$ CQ or $100 \mathrm{nM} \mathrm{KU} .{ }^{*} p<0.05,{ }^{* *} p<0.01$, and ${ }^{* * *} p<0.001$.

4 Gy IR for $24 \mathrm{hr}$, while CAL27 cells were treated with $1.25 \mu \mathrm{M} \mathrm{PL}$ and/or $2 \mathrm{GyIR}$ for $24 \mathrm{hr}$. As shown in Figures 2(g) and 2(h), PL and IR treatment alone could increase apoptosis. When PL and IR were combined together, the apoptosis levels were significantly increased by 3.65- and 2.84-fold comparing with the IR group, in separate SCC9 and CAL27 cells (Figures 2(i) and 2(j); ${ }^{* * *} p<0.001$ ). Collectively, these results show that combination PL and IR treatment modulates apoptosis, rendering TSCC cells more apoptotic in a potent and synergistic manner.

3.4. PL Inhibits the IR-Induced Phosphorylation of ATM and $N F-\kappa B$ in TSCC Cells. To probe the mechanism of radiosensitization effect of PL in TSCC, we used ATM activator CQ to examine the induction effect of cell cycle and apoptosis by PL and IR combination. Compared with PL + IR treatment, pretreatment of $5 \mu \mathrm{M}$ CQ for $1 \mathrm{hr}$ decreased the G2/M phase population by $46.52 \%$ in SCC 9 cells and $66.44 \%$ in CAL27 cells (Figures 2(a)-2(f)). While compared with $\mathrm{PL}+\mathrm{IR}$ treatment, pretreatment of $5 \mu \mathrm{M}$ CQ for $1 \mathrm{hr}$ decreased the apoptosis rate by $54.68 \%$ in SCC9 cells and $57.04 \%$ in CAL27 cells (Figures $2(\mathrm{~g})-2(\mathrm{j})$ ).

Furthermore, RT-PCR and Western blot were used to examine the expression level of ATM and NF- $\kappa \mathrm{B}$ in both cells. Comparing with the IR single group, the mRNA level of ATM was decreased by $35.98 \%$ and the mRNA level of NF- $\kappa \mathrm{B}$ was decreased by $64.94 \%$ after the combined treatment of PL and IR in SCC9 cells (Figures 3(a) and 3(b); $\left.{ }^{* * *} p<0.001\right)$; the mRNA level of ATM was decreased by $46.32 \%$ and the mRNA level of NF- $\kappa B$ was decreased by $65.17 \%$ after the combined treatment of PL and IR in CAL27 cells (Figures $3(\mathrm{c})$ and $3(\mathrm{~d}) ;{ }^{* *} p<0.001$ ). The protein levels of ATM, p-ATM, NF- $\kappa \mathrm{B}$, and $\mathrm{p}-\mathrm{NF}-\kappa \mathrm{B}$ were all increased after the treatment of IR. However, when IR combined with $\mathrm{PL}$, these proteins were all downregulated (Figures 4(a) and $\left.4(\mathrm{~b}) ;{ }^{* * *} p<0.001\right)$. Furthermore, we applied ATM activator $\mathrm{CQ}$ and inhibitor KU to examine the exact modulation role 

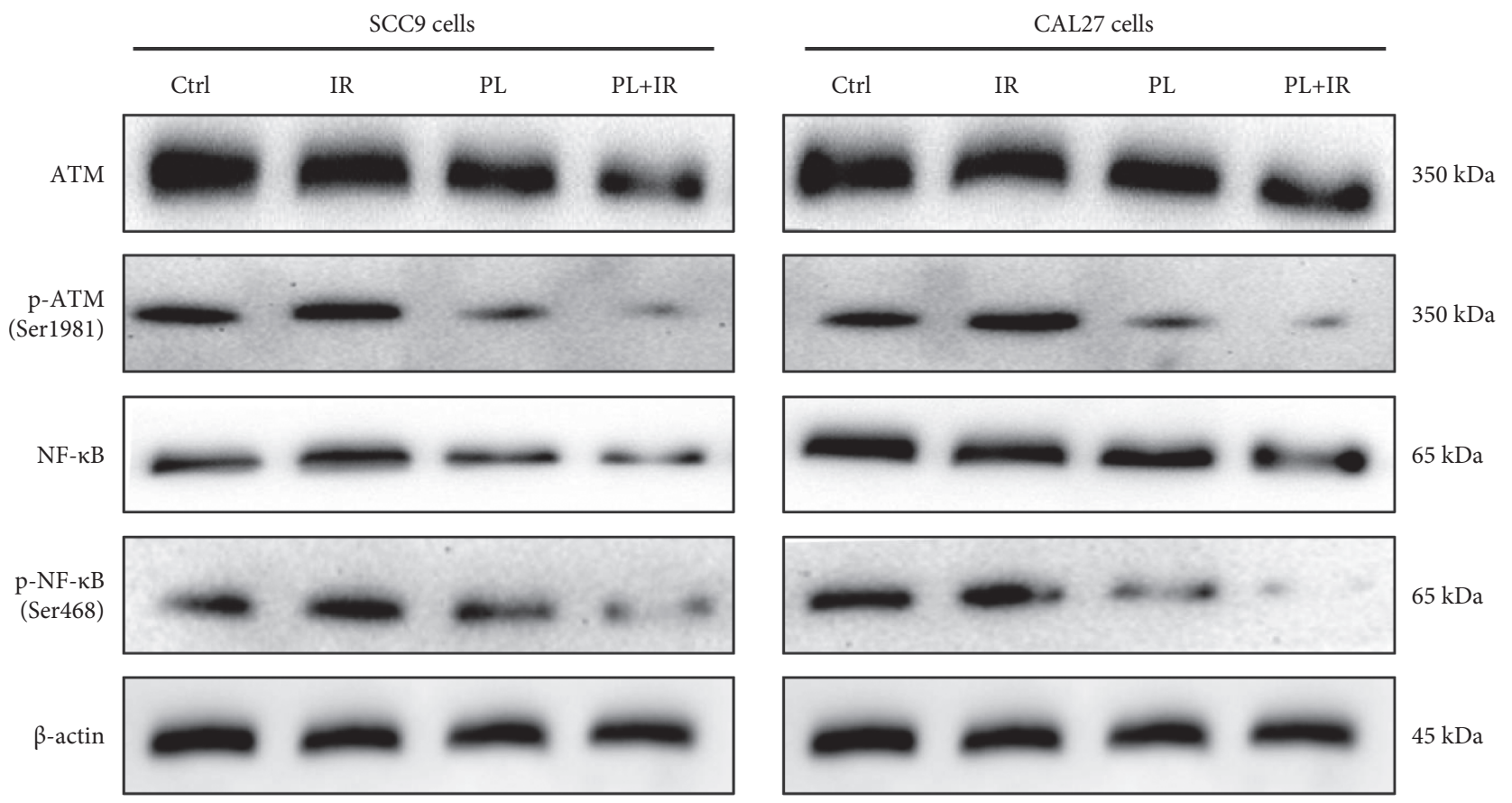

(a)
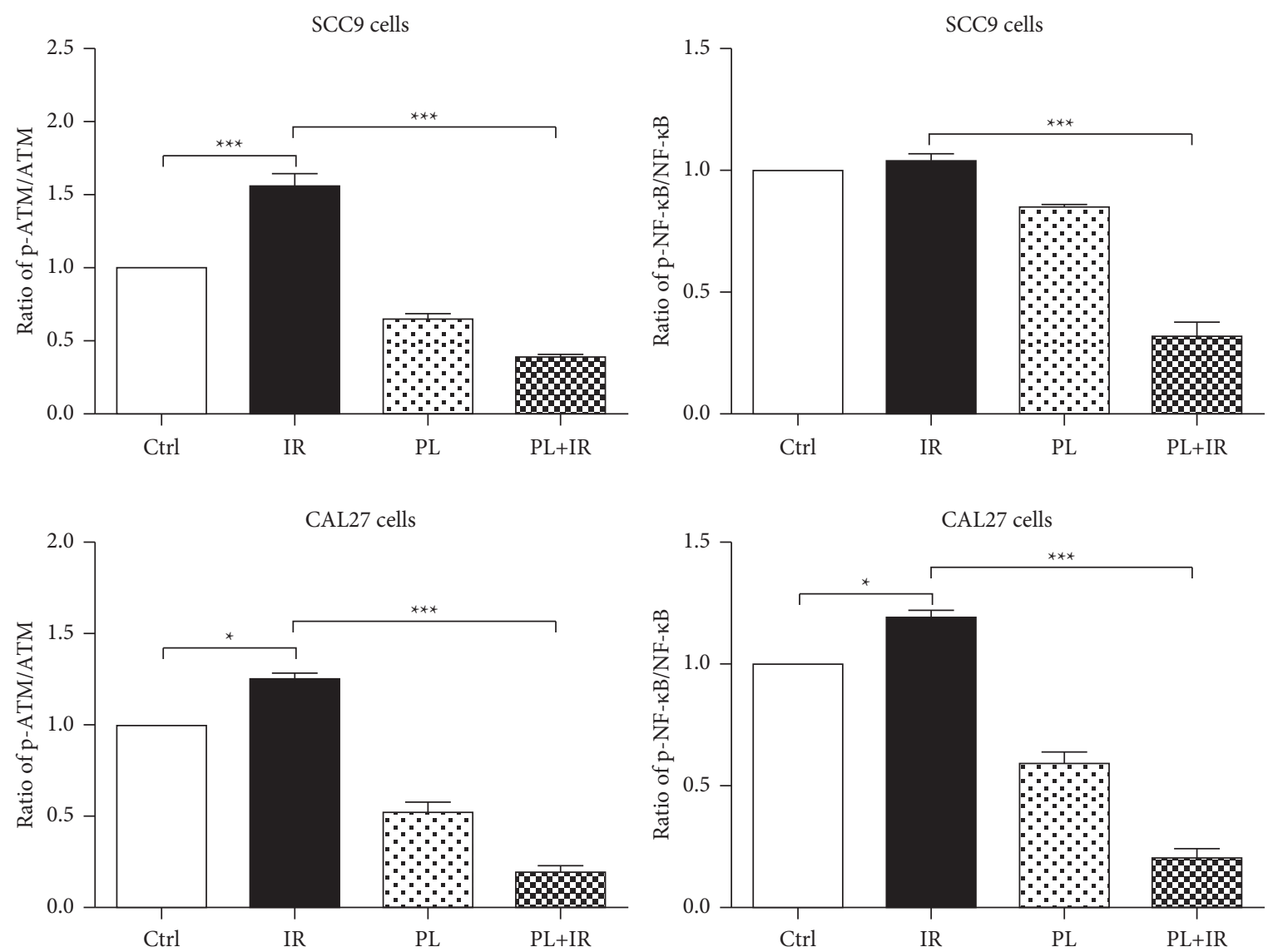

(b)

Figure 4: Continued. 

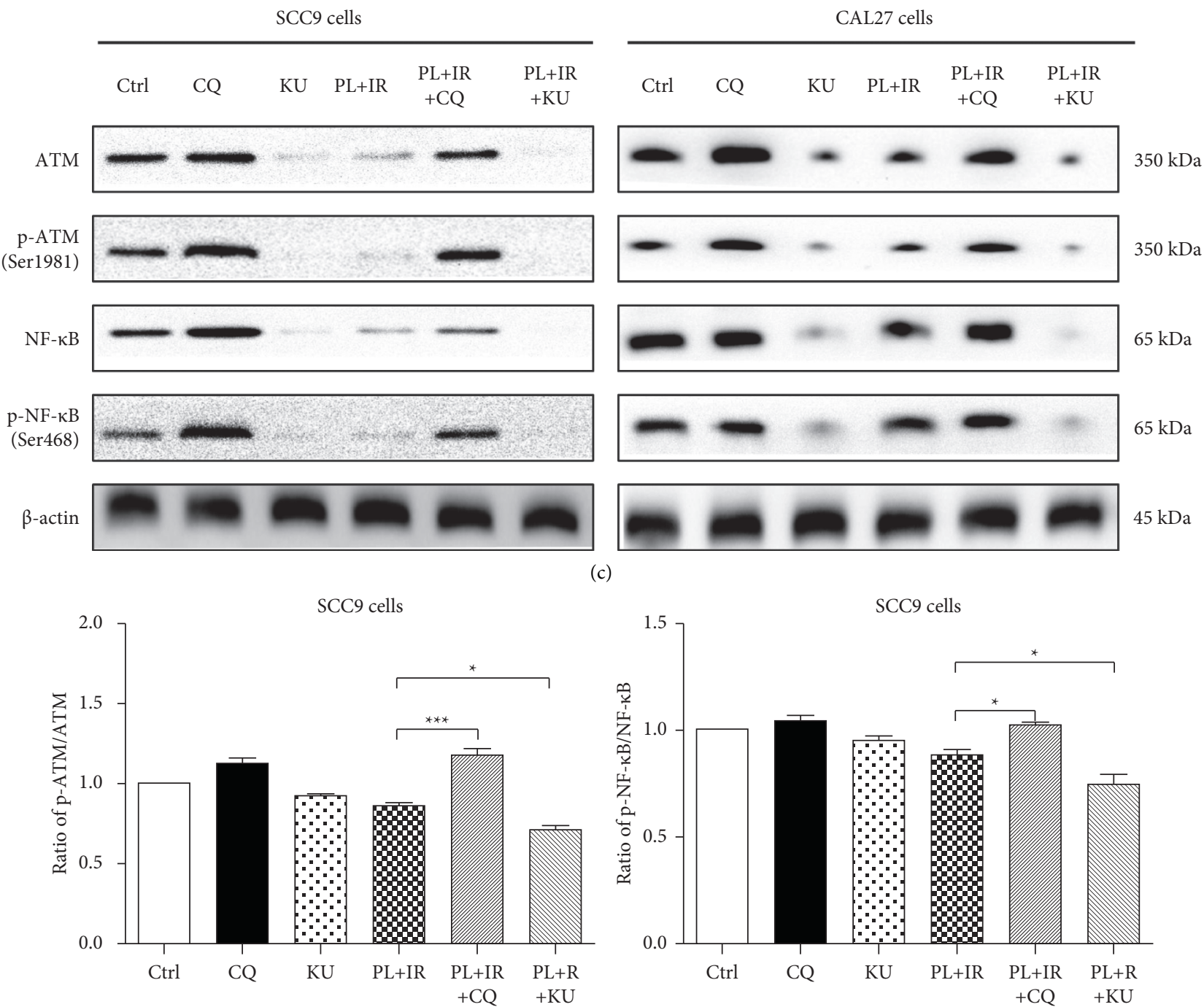

$65 \mathrm{kDa}$

(c)

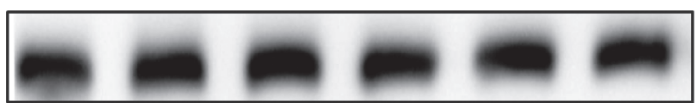

$45 \mathrm{kDa}$
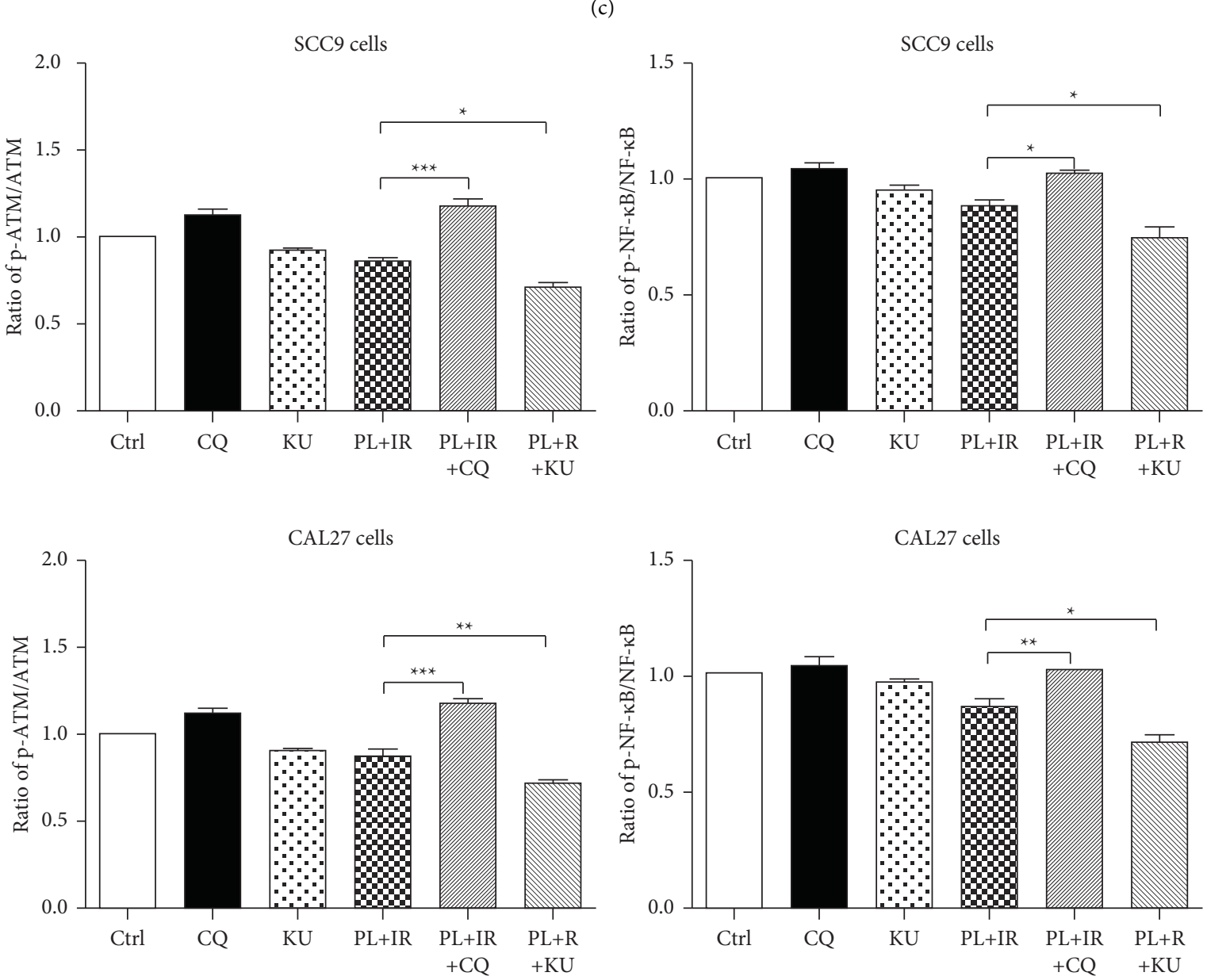

(d)

FIgure 4: Combined PL and IR inhibit ATM signaling in TSCC cells. (a) Representative bolts of ATM, p-ATM, NF- $\kappa B$, and p-NF- $\kappa B$ in SCC9 and CAL27 cells after the treatment of IR, PL, and IR + PL for $24 \mathrm{hr}$. (c) Representative bolts of ATM, p-ATM, NF- $\kappa B$, and p-NF- $\kappa B$ in SCC9 and CAL27 cells after the treatment of CQ, KU, PL + IR, PL + IR + CQ, and PL + IR + KU for 24 hr. (b, d) Bar graphs showing the ratio of p-AMT/ATM and p-NF- $\kappa \mathrm{B} / \mathrm{NF}-\kappa \mathrm{B}$ when the cells were treated with various groups for $24 \mathrm{hr} .{ }^{*} p<0.05,{ }^{* *} p<0.01$, and ${ }^{* * *} p<0.001$. 
of PL on ATM. mRNA level of ATM could efficiently be upregulated by $5 \mu \mathrm{M}$ CQ while downregulated by $100 \mathrm{nM}$ KU. Noteworthy, modulation ATM significantly affected the mRNA level of NF- $\kappa B$. CQ could elevate the level of NF- $\kappa B$ by $1.66-$ fold, and KU could decrease the level of NF- $\kappa B$ by $38.33 \%$ (Figure $3 ;^{* * *} p<0.001$ ). This hints that ATM is a potent upstream of NF- $\mathrm{kB}$. In addition, pretreatment of $5 \mu \mathrm{M} \mathrm{CQ}$ for $1 \mathrm{hr}$ reversed PL and IR combination-induced downregulation of p-ATM and p-NF-kB (Figures 4(c)and $4(d)$ ).

Collectively, these results showed that PL significantly sensitized TSCC cells to radiation by inhibiting the IR-induced phosphorylation of ATM and NF-kB.

\section{Discussion}

TSCC is one of the most lethal cancer types in the head and neck region, and the five-year survival rate has not improved significantly [2]. Radiotherapy is an important method for treating TSCC by inducing DNA breaks [16].

PL is a naturally-derived active naphthoquinone which shows promising medicinal properties. Our group focuses on the anticancer property of PL for many years. The main findings are that PL could efficiently kill tongue cancer cells via cell cycle arrest, apoptosis, and autophagy induction through modulating PI3K/Akt/mTOR signaling. Ono et al. was the first to show that PL and cisplatin could synergistically enhance apoptosis in OSCC cells [14]. Similarly, in our recent research, the combination treatment of PL and cisplatin resulted in a synergistic inhibition of TSCC viability [13]. In the present study, we revealed that PL could enhance IR sensitivity in TSCC cells. The combination of $1.25 \mu \mathrm{M}$ PL and $4 \mathrm{~Gy}$ IR exhibited the lowest CI value in SCC9 cells, and the combination of $1.25 \mu \mathrm{M}$ PL and 2 Gy IR exhibited the lowest CI value in CAL27 cells which indicated the best synergistic effect. Due to the reduced dosage of PL and IR when combined together, it will be beneficial to minimize the side effects of PL and/or IR to the normal cells or tissues.

The radiation sensitivity of cancer cells changes according to the phase of the cell cycle. There is a resistance in the G0/G1 phase, and the resistance reaches the highest level in the late $S$ phase. After entering the G2/M phase, the cell sensitivity increased again [16]. In our previous studies, PL could arrest TSCC cells at the G2/M phase in a concentration- and time-dependent manner. The expression level of Cdc2 and Cyclin B1 was decreased, while the expression level of p21, p27, and p53 was increased [11]. In this present study, we found that combined PL and IR treatment significantly promotes $\mathrm{G} 2 / \mathrm{M}$ arrest which is an underlying mechanism of radiosensitization of PL in TSCC cells.

Agents targeting apoptosis would be expected to be used in combination with radiotherapy to delay tumor growth [17]. Palbociclib, the CDK4/6 inhibitor, can promote apoptosis of bladder cancer cells by inhibition of DNA repair following radiotherapy [18]. The Bcl-2 and Bcl-XL inhibitor S44563 could significantly enhance the sensitivity of smallcell lung cancer cells to radiation [19]. Our present research revealed that PL with the concentration of $1.25 \mu \mathrm{M}$ could greatly induce apoptosis to enhance the radiosensitivity of TSCC cells. In this study, we did not examine whether PLinduced apoptosis in TSCC cells was through the intrinsic or extrinsic pathway. Based on our previous data, both intrinsic and extrinsic pathways are involved in the PL-induced apoptosis in TSCC cells $[11,20]$. Other groups reported that PL-induced apoptosis via the intrinsic mitochondrial pathway in non-small-cell lung cancer A549 cells [21]. PL could also enhance TRAIL-induced apoptosis in leukemic Kasumi-1 cells [22]. Collectively, the present research is the first to report the radiosensitizing effect of PL in TSCC cells via induction of $\mathrm{G} 2 / \mathrm{M}$ arrest and apoptosis.

ATM belongs to the phosphoinositide 3-kinase family which involves in cell proliferation, survival, and metabolism. ATM can respond to radiation-induced DNA damage and launch downstream repair proteins and cell cycle checkpoints to render cancer cells survival, so inhibiting the expression of ATM can appropriately increase the sensitivity of cells to radiation $[4,23]$. In the present study, the IR single treatment group increased the phosphorylation of ATM in TSCC cells. In the combined treatment of PL and IR, the level of p-ATM was decreased comparing with the IR group. Pretreatment of ATM activator CQ could reverse the induction effect of apoptosis and G2/M arrest by the PL and IR combination. In addition, CQ could reverse PL and IR combination-induced downregulation of p-ATM and p-NF- $\mathrm{kB}$. ATM inhibitors will probably block NF- $\kappa B$ activation that is induced by radiotherapy [24]. NF- $\kappa B$ can regulate the survival and malignancy of many cancers including tongue cancer $[25,26]$. Our research found that ATM inhibitor KU could decrease the mRNA level of NF- $\kappa B$ in TSCC cells. IR single treatment activated NF- $\mathrm{kB}$ in both mRNA and protein level, while PL combined with IR significantly decreased the expression level of NF- $\kappa B$. CQ reversed PL-induced NF- $\kappa B$ inhibition. All these demonstrate that PL can enhance radiosensitivity by inhibiting ATM signaling.

In conclusion, we provide evidence that the combination of PL and IR efficiently facilitates the G2/M arrest and apoptotic activity by downregulating ATM in TSCC cells. PL was a potent radiosensitizer. Although preclinical and clinical investigations are still necessary, combined treatment of PL and IR seems to be a potentially attractive modality for tongue cancer.

\section{Data Availability}

The data used to support the findings of this study are included within the article.

\section{Conflicts of Interest}

The authors report no conflicts of interest for this work.

\section{Acknowledgments}

This work was financially supported by the National Natural Science Foundation of China (81860480), Youth Science 
Fund Project of the Science and Technology Department of Jiangxi Province (20181BAB215022), and Young Teachers Research and Development Fund Project of Nanchang University (4209-16100009-PY201818).

\section{References}

[1] Y.-J. Kim and J. H. Kim, "Increasing incidence and improving survival of oral tongue squamous cell carcinoma," Scientific Reports, vol. 10, no. 1, p. 7877, 2020.

[2] B. R. Campbell, J. L. Netterville, R. J. Sinard et al., "Early onset oral tongue cancer in the United States: a literature review," Oral Oncology, vol. 87, pp. 1-7, 2018.

[3] M.-K. N. D. Hutchinson, M. Mierzwa, and N. J. D'Silva, "Radiation resistance in head and neck squamous cell carcinoma: dire need for an appropriate sensitizer," Oncogene, vol. 39, no. 18, pp. 3638-3649, 2020.

[4] N. Malaquin, A. Carrier-Leclerc, M. Dessureault, and F. Rodier, "DDR-mediated crosstalk between DNA-damaged cells and their microenvironment," Frontiers in Genetics, vol. 6, p. 94, 2015.

[5] G. Dunphy, S. M. Flannery, J. F. Almine et al., "Non-canonical activation of the DNA sensing adaptor STING by ATM and IFI16 mediates NF- $\mathrm{kB}$ signaling after nuclear DNA damage," Molecular Cell, vol. 71, no. 5, pp. 745-760.e5, 2018.

[6] B. Eluard, C. Thieblemont, and V. Baud, "NF- $\kappa$ B in the new era of cancer therapy," Trends in cancer, vol. 6, no. 8, pp. 677-687, 2020.

[7] A. Mazumder, C. Cerella, and M. Diederich, "Natural scaffolds in anticancer therapy and precision medicine," Biotechnology Advances, vol. 36, no. 6, pp. 1563-1585, 2018.

[8] S. K. Tripathi, M. Panda, and B. K. Biswal, "Emerging role of plumbagin: cytotoxic potential and pharmaceutical relevance towards cancer therapy," Food and Chemical Toxicology, vol. 125, pp. 566-582, 2019.

[9] Y. Lin, Y. Chen, S. Wang et al., "Plumbagin induces autophagy and apoptosis of SMMC-7721 cells in vitro and in vivo," Journal of Cellular Biochemistry, vol. 120, no. 6, pp. 98209830, 2019.

[10] N. Sakunrangsit and W. Ketchart, "Plumbagin inhibited AKT signaling pathway in HER-2 overexpressed-endocrine resistant breast cancer cells," European Journal of Pharmacology, vol. 868, p. $172878,2020$.

[11] S. T. Pan, Y. Qin, Z. W. Zhou et al., "Plumbagin induces G2/M arrest, apoptosis, and autophagy via p38 MAPK- and PI3K/ Akt/mTOR-mediated pathways in human tongue squamous cell carcinoma cells," Drug Design, Development and Therapy, vol. 9, pp. 1601-1626, 2015.

[12] A. Kawiak, A. Domachowska, and E. Lojkowska, "Plumbagin increases paclitaxel-induced cell death and overcomes paclitaxel resistance in breast cancer cells through ERK-mediated apoptosis induction," Journal of Natural Products, vol. 82, no. 4, pp. 878-885, 2019.

[13] D. Xue, S. T. Pan, X. Zhou et al., "Plumbagin enhances the anticancer efficacy of cisplatin by increasing intracellular ROS in human tongue squamous cell carcinoma," Oxidative Medicine and Cellular Longevity, vol. 2020, Article ID 5649174, , 2020.

[14] T. Ono, A. Ota, K. Ito et al., "Plumbagin suppresses tumor cell growth in oral squamous cell carcinoma cell lines," Oral Diseases, vol. 21, no. 4, pp. 501-511, 2015.

[15] T.-C. Chou and P. Talalay, "Quantitative analysis of doseeffect relationships: the combined effects of multiple drugs or enzyme inhibitors," Advances in Enzyme Regulation, vol. 22, pp. 27-55, 1984.

[16] M. A. Morgan and T. S. Lawrence, "Molecular pathways: overcoming radiation resistance by targeting DNA damage response pathways," Clinical Cancer Research, vol. 21, no. 13, pp. 2898-2904, 2015.

[17] B. A. Carneiro and W. S. El-Deiry, "Targeting apoptosis in cancer therapy," Nature Reviews Clinical Oncology, vol. 17, no. 7, pp. 395-417, 2020.

[18] G. Zhang, F. e. Ma, L. Li et al., "Palbociclib triggers apoptosis in bladder cancer cells by Cdk2-induced Rad9-mediated reorganization of the Bak.Bcl-xl complex," Biochemical Pharmacology, vol. 163, pp. 133-141, 2019.

[19] Y. Loriot, P. Mordant, D. Dugue et al., "Radiosensitization by a novel Bcl-2 and Bcl-XL inhibitor S44563 in small-cell lung cancer," Cell Death \& Disease, vol. 5, no. 9, p. e1423, 2014.

[20] S. T. Pan, Y. Qin, Z. W. Zhou et al., "Plumbagin suppresses epithelial to mesenchymal transition and stemness via inhibiting Nrf2-mediated signaling pathway in human tongue squamous cell carcinoma cells," Drug Design, Development and Therapy, vol. 9, pp. 5511-5551, 2015.

[21] S. K. Tripathi, K. R. R. Rengasamy, and B. K. Biswal, "Plumbagin engenders apoptosis in lung cancer cells via caspase- 9 activation and targeting mitochondrial-mediated ROS induction," Archives of Pharmacal Research, vol. 43, no. 2, pp. 242-256, 2020.

[22] X. Kong, J. Luo, T. Xu et al., "Plumbagin enhances TRAILinduced apoptosis of human leukemic Kasumi-1 cells through upregulation of TRAIL death receptor expression, activation of caspase- 8 and inhibition of cFLIP," Oncology Reports, vol. 37, no. 6, pp. 3423-3432, 2017.

[23] J. M. Murray and A. M. Carr, "Integrating DNA damage repair with the cell cycle," Current Opinion in Cell Biology, vol. 52, pp. 120-125, 2018.

[24] Z.-H. Wu and S. Miyamoto, "Induction of a pro-apoptotic ATM-NF- $\kappa$ B pathway and its repression by ATR in response to replication stress," The EMBO Journal, vol. 27, no. 14, pp. 1963-1973, 2008.

[25] S. Ke, R.-C. Li, F.-K. Meng, and M.-H. Fang, "NKILA inhibits $\mathrm{NF}-\mathrm{\kappa B}$ signaling and suppresses tumor metastasis," Aging, vol. 10, no. 1, pp. 56-71, 2018.

[26] Y. Gu, H. Liu, F. Kong et al., "miR-22/KAT6B axis is a chemotherapeutic determiner via regulation of PI3k-Akt-NF$\mathrm{\kappa B}$ pathway in tongue squamous cell carcinoma," Journal of Experimental \& Clinical Cancer Research, vol. 37, no. 1, p. 164, 2018. 